\title{
Effects of diet on dimensions, density and sinking rates of fecal pellets of the copepod Acartia tonsa
}

\author{
Leah R. Feinberg*, Hans G. Dam** \\ Department of Marine Sciences, University of Connecticut, Groton, Connecticut 06340, USA
}

\begin{abstract}
The effects of food type and concentration on fecal pellet characteristics of the calanoid copepod Acartia tonsa were examined in the laboratory. Copepods were fed several autotrophic and heterotrophic diets, including the diatoms Thalassiosira weissflogii and Chaetoceros neogracile, the photosynthetic flagellates Rhodomonas lens and Tetraselmis sp., the heterotrophic dinoflagellate Oxyrrhis marina, the heterotrophic flagellates Cafeteria sp. and Oikomonas sp., and the scuticociliate Uronema sp. Copepods were fed both a low $\left(\sim 100-300 \mu \mathrm{g} \mathrm{C} \mathrm{l}^{-1}\right)$ and a high $\left(\sim 500-1500 \mu \mathrm{C}^{-1}\right)$ concentration of these diets. Length, width and density of the resulting fecal pellets were measured. Sinking rates were calculated from a semi-empirical model based on these parameters. In general, diets that resulted in large pellets also resulted in the least dense pellets. Ciliate and diatom diets produced the largest pellets and resulted in the fastest estimated sinking rates. Heterotrophic flagellate and heterotrophic dinoflagellate diets resulted in the most dense and slowest sinking pellets. Within a diet, significant differences in pellet characteristics were often found between food concentrations, but there was no consistent pattern of increasing or decreasing pellet size or density with an increase in food concentration. The coefficient of variation of pellet sinking rates across all diets in this study was nearly $40 \%$. This indicates the uncertainty in estimated sinking rates if diet is not considered. Combining the sinking rates from this study with published diet-specific fecal pellet degradation rates, we define an L-ratio, the fraction of pellet degradation per unit length of sinking. The L-ratio may be useful in predicting the degree of recycling of pellets within the mixed layer. Diatoms show the lowest L-ratios and photosynthetic flagellates the highest L-ratios.
\end{abstract}

KEY WORDS: Fecal pellets $\cdot$ Vertical flux $\cdot$ Copepods $\cdot$ Diet $\cdot$ Acartia tonsa

\section{INTRODUCTION}

While small single celled phytoplankton account for most of the primary production in the oceans, most of the downward flux of organic material is in the form of larger (>63 $\mathrm{\mu m}$ ) particles and aggregates (McCave 1975, Pilskaln and Honjo 1987, Gardner 1997). One of the primary mechanisms of biologically mediated aggregation of small particles is through the production of zooplankton fecal pellets (Turner \& Ferrante 1979). Copepods are ubiquitous and the most common pelagic metazoans present year-round in the ocean. They therefore have the potential to contribute sub-

\footnotetext{
- Present address: NOAA, NMFS/NWFSC/Hatfield Marine Science Center, Newport, Oregon 97365, USA

"Addressee for correspondence.

E-mail: hgdam@uconnvm.uconn.edu
}

stantially to the total production of fecal matter, and hence the downward flux of organic material.

The flux of fecal pellets in the water column, $F\left(\mathrm{~g} \mathrm{~m}^{-2}\right.$ $\mathrm{d}^{-1}$ ), may be approximated by:

$$
F=\bar{C} \times \bar{V}+K_{L}(\partial C / \partial Z)
$$

where $\bar{C}=$ mean concentration of fecal pellets $\left(\mathrm{g} \mathrm{m}^{-3}\right), \bar{V}$ $=$ mean sinking velocity of the pellets $\left(\mathrm{m} \mathrm{d}^{-1}\right), K_{2}=$ vertical eddy diffusion coefficient $\left(\mathrm{m}^{2} \mathrm{~d}^{-1}\right)$ and $\partial \mathrm{C} / \partial Z=$ vertical gradient in fecal pellet concentration $\left(\mathrm{g} \mathrm{m}^{-4}\right) . \bar{C} \times \bar{V}$ represents the flux due to gravitational sinking, whereas $K_{z}(\partial C / \partial Z)$ represents the flux due to turbulent vertical mixing. Fecal pellet concentration is a function of zooplankton concentration and pellet production and degradation rates. The magnitude of the velocity term determines the fraction of the pellet production exported from the euphotic zone. Slowly sinking pellets are more likely to be recycled or decomposed before leaving the 
warmer, more physically and biologically active euphotic zone (Dagg \& Walser 1986, Small et al. 1987).

This study focuses on the examination of parameters that affect the gravitational sinking rates of fecal pellets. Sinking velocities due to turbulent eddy motion $\left(V^{\prime}\right)$ can be approximated by $K_{z} / L_{\mathrm{b}}$, where $L_{\mathrm{b}}$ is the buoyancy length scale. Employing typical oceanic values of $K_{z}=5.2 \mathrm{~m}^{2} \mathrm{~d}^{-1}$ and $L_{\mathrm{b}}=10 \mathrm{~m}$ (Mann \& Lazier 1996) yields $V^{\prime}=0.52 \mathrm{~m} \mathrm{~d}^{-1}$, which is much lower than the typical sinking rate for zooplankton fecal pellets (e.g. Small et al. 1979), although values of $V^{\prime}$ in estuarine environments can be substantially higher (Tang et al. 1998). The gravitational sinking rate of a fecal pellet is primarily a function of its size, shape and specific gravity (Komar et al. 1981). Pellet size is known to increase with increasing animal size (Paffenhöfer \& Knowles 1979, Uye \& Kaname 1993) and with increasing food concentration to a point of saturation (Dagg \& Walser 1986, Tsuda \& Nemoto 1990, Butler \& Dam 1994). Pellet size can also be affected by the diet consumed. For instance, Bienfang (1980) reported that copepods fed a diatom diet produced pellets smaller than those produced on a flagellate diet. The opposite was observed by Turner (1977).

Despite their relevance to sinking velocities, fecal pellet densities have rarely been measured directly. Studies that included this measurement are consistent in the range of values reported (1.04 to $\left.1.19 \mathrm{~g} \mathrm{~cm}^{-3}\right)$, and the variability is often associated with changes in food type or quality (Dilling \& Alldredge 1993, Urban et al. 1993, Butler \& Dam 1994). The conclusions drawn from these studies as to the effects of specific types of foods on pellet densities are conflicting. Urban et al. (1993), in a seasonal study, observed that the densest fecal pellets produced by the copepod Calanus finmarchicus in the natural environment coincided with times when the fecal pellets consisted of mainly nanoplankters, bacteria, ciliates and dinoflagellates, not diatoms. Bienfang (1980) did not measure fecal pellet densities, but inferred from volume and sinking rate measurements that fecal pellets produced by copepods fed on a diet consisting of primarily diatoms were more dense than those from a flagellate diet. Even when copepods are fed a single diatom diet, differences in growth stage of the food can result in significant differences in pellet densities (Butler \& Dam 1994). The authors of past studies suggest that fecal pellet densities are most likely a function of either the density of the compounds contained within the pellets or of the level of compaction of these components (Bienfang 1980, Dilling \& Alldredge 1993, Urban et al. 1993).

The gravitational sinking velocity of copepod fecal pellets can be parameterized by a semi-empirically derived version of Stokes' law: for cylindrical particles at low Reynold's numbers (Komar et al. 1981)

$$
V=0.0790 \frac{1}{v}\left(\rho_{\text {particle }}-\rho_{\text {water }}\right) g L^{2}\left(\frac{L}{D}\right)^{-1.664}
$$

where $V=$ sinking velocity $\left(\mathrm{cm} \mathrm{s}^{-1}\right), v=$ viscosity of seawater $\left(\mathrm{g} \mathrm{cm}^{-1} \mathrm{~s}^{-1}\right), g=$ acceleration due to gravity (981 $\mathrm{cm} \mathrm{s}^{-1}$ ), $L=$ length of pellet $(\mathrm{cm}), D=$ diameter of pellet $(\mathrm{cm})$, and $\rho=$ density $\left(\mathrm{g} \mathrm{cm}^{-3}\right)$. The purpose of this study was to determine the effects of diet composition and concentration on those parameters that determine the gravitational sinking rate of fecal pelletslength, width and density. Although most copepods are known to be opportunistic omnivores (Turner 1984 , Kleppel 1993), to date a comprehensive analysis of diet and food concentration on these fecal pellet parameters has not been undertaken. Through controlled laboratory experiments we tested the null hypothesis that there would be no significant differences in fecal pellet characteristics associated with changes in food composition or concentration.

\section{MATERIALS AND METHODS}

The effects of food type and concentration on length, width and density of pellets were studied under controlled laboratory conditions. Each experimental incubation consisted of feeding the omnivorous copepod Acartia tonsa a low and a high concentration (see 'Acclimation and incubation') of several autotrophic and heterotrophic diets (Table 1).

Copepod and prey culture conditions. All copepods and their foods were grown in culture in a walk-in environmental chamber at $19^{\circ} \mathrm{C}\left( \pm 1^{\circ} \mathrm{C}\right)$ on a $12 \mathrm{~h}$ light:12 h dark cycle. Cohorts of Acartia tonsa were grown from the eggs of copepods collected from Long Island Sound (USA) and kept on a mixture of Isochrysis galbana, Rhodomonas lens, Tetraselmis sp., Thalassiosira weissflogii, and Oxyrrhis marina at a total concentration of approximately $500 \mu \mathrm{g} \mathrm{Cl}^{-1}$ The copepods were raised in age cohorts to ensure that all adults used in an experiment were grown in similar conditions and were of about the same age. The copepod cultures were grown in 2 to $4 \mathrm{l}$ polycarbonate containers and bubbled gently with filtered air. At least $50 \%$ of the culture food suspension was replaced 3 times a week.

All diatoms (Table 1) were maintained in exponential growth in f/2 medium (Guillard 1975). Photosynthetic flagellates and dinoflagellates were kept in exponential growth in $\mathrm{f} / 2$ medium without silica (Guillard 1975). Heterotrophic dinoflagellates were grown in a medium of $0.2 \mu \mathrm{m}$ filtered seawater with the ironEDTA and trace metal component of $\mathrm{f} / 2$ (proportions as in Gifford 1993). They were fed Isochrysis galbana and Chroomonas salina. Small heterotrophic flagellates 
were grown in a medium of sterilized, $0.2 \mu \mathrm{m}$ filtered seawater enriched with sterilized grains of rice and brought to a final concentration of $0.2 \%$ yeast extract (Caron 1993). These heterotrophic flagellates fed upon the bacteria with which they were isolated. Ciliates were grown in a medium of sterilized, $0.2 \mu \mathrm{m}$ filtered seawater. The medium was brought to a concentration of $0.2 \%$ yeast extract to sustain the bacteria upon which the ciliates fed.

Acclimation and incubation. Active adult females with intact appendages were selected from the Acartia tonsa cultures and acclimated to experimental conditions for $48 \mathrm{~h}$. The low food concentration was a nominally limiting level of -100 to $200 \mu \mathrm{g} \mathrm{Cl}^{-1}$. The high food concentration was nominally saturating at $>500 \mu \mathrm{g} \mathrm{C} \mathrm{l}^{-1}$ (Kiorboe et al. 1985, Houde \& Roman 1987, Berggreen et al. 1988, Butler \& Dam 1994). The designation of limiting and saturating concentrations for the production of fecal pellets by $A$. tonsa is poorly defined in the literature for the diets used in this study. These concentrations were chosen as a best estimate from the ingestion responses shown by Kiorboe et al. (1985) and Houde \& Roman (1987) as well as the fecal pellet production and volume responses shown by Butler \& Dam (1994). To prepare dilutions for the experiments, phytoplankton cell concentration and volume were measured (triplicate subsamples) using an Elzone 280 particle counter and their carbon content estimated from volume using the conversion factor of $0.11 \mathrm{pg} \mathrm{C} \mu^{-3}$ (Strathmann 1967). Heterotrophic dinoflagellates and ciliates were counted and their lengths and widths measured at $100 \times$ magnification using an inverted microscope. Their volume was estimated assuming a cylindrical shape. Carbon contents were calculated using a conversion factor of $0.20 \mathrm{pg}$ $\mu \mathrm{m}^{-3}$ for heterotrophic dinoflagellates $<60 \mu \mathrm{m}$ (Evelyn Lessard pers. comm.) and $0.22 \mathrm{pg} \mathrm{C} \mathrm{mm}^{-3}$ for the ciliates (Stoecker et al. 1994). Heterotrophic flagellates were stained with acridine orange and measured at $1200 \times$ magnification on an epifluorescence microscope. Volumes were estimated from cell diameter assuming a spherical shape. Carbon content was initially estimated with a conversion factor of $0.18 \mathrm{pg}$ $\mathrm{C} \mu \mathrm{m}^{-3}$ derived from elemental analysis (Carlo Erba EA 1108 CHN analyzer; authors' unpubl, data) and cell volumes of the cultures. Combusted glass-fiber GF/D filters with a $2.7 \mathrm{\mu m}$ pore size were used for this analysis in order to minimize the contribution to POC by bacteria in the cultures. At a later date, actual carbon concentrations were measured for all diets from samples collected for $\mathrm{CHN}$ analysis at the time of the incubations (see 'Sample processing' and Table 1).

Triplicate 2 l bottles containing 10 copepods each were used for each experimental diet and concentration. Bottles were filled to the top and kept on a plankton wheel (end-over-end bottle rotation at $2 \mathrm{rpm}$ ) in the environmental chamber at $19 \pm 1^{\circ} \mathrm{C}$. All incubations were run for $12 \mathrm{~h}$ at night and in the dark to coincide with the period of enhanced feeding in Acartia tonsa (Stearns 1986, Durbin et al. 1990). Our aim was to maximize ingestion and presumably fecal pellet production while minimizing the time for pellet degradation and

Table 1. Summary of diets and food concentrations used in experiments. ESD = equivalent spherical diameter; low food and high food: low and high food concentrations treatments. NMFS = National Marine Fisheries Service; EPA = Environmental Protection Agency; WHOI = Woods Hole Oceanographic Institution (Woods Hole, MA, USA)

\begin{tabular}{|c|c|c|c|c|c|}
\hline Functional group & Species & $\mathrm{ESD}(\mu \mathrm{m})$ & Origin/strain & $\begin{array}{l}\text { sured co } \\
\text { Low food }\end{array}$ & $\begin{array}{l}\text { ac. }\left(\mu g \mathrm{Cl}^{-1}\right) \\
\text { High food }\end{array}$ \\
\hline Diatom & Thalassiosira weissflogii & 11.0 & $\begin{array}{l}\text { NMFS Collection } \\
\text { (Milford, CT, USA) }\end{array}$ & 142 & 712 \\
\hline Diatom & Chaetoceros neogracile & 5.4 & $\begin{array}{l}\text { NMFS Collection } \\
\text { (Milford, CT, USA) }\end{array}$ & 122 & 610 \\
\hline Flagellate & Rhodomonas lens & 6.5 & $\begin{array}{l}\text { NMFS Collection } \\
\text { (Milford, CT, USA) }\end{array}$ & 162 & 814 \\
\hline Flagellate & Tetraselmis sp. & 7.5 & EPA (Narragansett, RI, USA) & 269 & 1346 \\
\hline Dinoflagellate & Heterocapsa triquetra & 12.8 & $\begin{array}{c}\text { Bigelow Laboratory (West Boothbay } \\
\text { Harbor, ME, USA) 'CCMP448' }\end{array}$ & 266 & 1334 \\
\hline Heterotrophic dinoflagellate & Oxyrrhis marina & 20.0 & $\begin{array}{l}\text { Bigelow Laboratory (West Boothbay } \\
\text { Harbor, ME, USA) 'CCMP1795', } \\
\text { isolated from Long Island Sound, USA }\end{array}$ & 167 & 835 \\
\hline Heterotrophic flagellate & Cafeteria sp. & 5.5 & D. A. Caron (WHOI) 'Cflag' & 360 & 1804 \\
\hline Heterotrophic flagellate & Oikomonas sp. & 4.5 & $\begin{array}{l}\text { D. A. Caron (WHOr) 'NB1', isolated } \\
\text { from Narragansett Bay, RI, USA }\end{array}$ & 238 & 1189 \\
\hline Ciliate & Uronema sp. & 11.0 & D. A. Caron (WHOI) 'BBcil' & 65 & 325 \\
\hline
\end{tabular}


reingestion. Hansen et al. (1996) found that pellets produced on a diet of the nanoflagellate Rhodomonas baltica displayed the highest degradation rate of the diets used in their experiments. Using the degradation rate calculated for this species, pellet volumes should decrease approximately $11 \%$ over a $12 \mathrm{~h}$ period. This would be the maximum decrease expected in our study since most of the pellets produced in the incubations of our study would be less than $12 \mathrm{~h}$ old Furthermore, no significant declines in pellet volume or density were observed by us during a $12 \mathrm{~h}$ incubation (observations made every $3 \mathrm{~h}$ ) with the photosynthetic flagellate Rhodomonas lens, suggesting that no measurable degradation had occurred.

Sample processing. At the beginning of each incubation replicate samples of the food cultures were collected for CHN analysis. Samples were filtered onto combusted glass fiber filters, dried at $60^{\circ} \mathrm{C}$ in a petri dish for $>24 \mathrm{~h}$ and processed using a Carlo Erba EA 1108 CHN Analyzer.

After each $12 \mathrm{~h}$ incubation, contents of the bottles were immediately wet-sieved through 200 and $30 \mu \mathrm{m}$ meshes to collect and separate the copepods and the fecal pellets, respectively. Copepods were preserved in formalin and then videotaped (standard rate black and white microscope-mounted video camera) and measured (prosome length and maximum width) within $72 \mathrm{~h}$ using an image analysis system (Optimas Corp). Pellets were collected and rinsed with filtered seawater and immediately videotaped for image analysis of length and width (precision $\approx 3 \mu \mathrm{m}$ ). At least 30 intact pellets from each bottle were measured. When possible, at least 50 intact pellets were collected from each bottle for density measurements.

Density measurement. Fecal pellet density was measured in a density gradient, using a modified version of the method described by Schwinghamer et al. (1991). Five dilutions were made using NALCO 1060 colloidal silica, sucrose and distilled water. These dilutions ranged in density from about 1.06 to $1.30 \mathrm{~g} \mathrm{~cm}^{-3}$. A $2 \mathrm{ml}$ volume of each dilution was poured gently into a $15 \mathrm{ml}$ centrifuge tube, beginning with the most dense and finishing with the least dense. These density gradients were refrigerated overnight, but were allowed to come to room temperature before use. The pellets collected from each of the experimental bottles were rinsed in filtered seawater and then placed in about $1 \mathrm{ml}$ of seawater, carefully pipetted onto the top surface of the density gradient and centrifuged for $30 \mathrm{~min}$ at approximately $3000 \mathrm{rpm}$ in a Fisher Scientific tabletop centrifuge. After centrifugation, $1 \mathrm{ml}$ aliquots were removed from the tube using a peristaltic pump. Due to slight mixing at the edges of the original density layers, and the observation that pellets often congregated in one portion of these layers, it was deemed more accu- rate to measure $1 \mathrm{ml}$ aliquots than the original $2 \mathrm{ml}$ added. Each aliquot was examined under a stereo microscope and the number of pellets per layer recorded. The density of each aliquot was then determined by measuring the volume of the liquid with a $5 \mathrm{ml}$ Hamilton syringe calibrated to $0.05 \mathrm{ml}$ and by measuring its mass using a Mettler PM2000 balance to $0.01 \mathrm{~g}$. Thus, the inherent error in density measurement is $1 \%$.

Sinking velocities. Pellet sinking velocities were calculated using Eq. (2). Viscosity was assumed to be $0.011 \mathrm{~g} \mathrm{~cm}^{-1} \mathrm{~s}^{-1}$ and the seawater density was assumed to be $1.0135 \mathrm{~g} \mathrm{~cm}^{-3}$. The mean pellet density per bottle was used in the sinking velocity calculations, since pellet densities measured were not associated specifically with individual pellets.

Statistical analysis. For many of the data sets it was not possible to use parametric statistics, usually due to unequal variance in the treatments even after the data had been log transformed. Therefore, the non-parametric Kruskal-Wallis test was used for analysis of differences between pellets from different diets and the functional groups defined in Table 1. The MannWhitney $U$-test was used to compare pellets from the 2 concentrations within a diet and for pairwise comparisons between diets.

\section{RESULTS}

Several tens to hundreds of fecal pellets were produced in all experiments; however, pellets produced on the dinoflagellate Heterocapsa triquetra diet were too poorly contained within a peritrophic membrane to measure reliably and thus are not included in the results presented here. Copepods fed heterotrophic flagellate diets produced fewer pellets than those fed other diets, which partially explains the increased error found for these measurements. Fecal pellets from different diets varied significantly in size, density and color. Diatom diets produced olive green to brown pellets, photosynthetic flagellate diets produced bright green pellets, the Oxyrrhis marina diet produced pink and orange pellets and the heterotrophic flagellate and ciliate diets resulted in white pellets. All pellets were essentially cylindrical in shape.

Because experiments were not performed simultaneously, mean copepod prosome length varied by approximately $15 \%$ over the course of all of the experiments. Body size may affect some of the variables of interest in our study. For instance, Uye \& Kaname (1994, and references therein) reported allometric relationships for pellet volume and animal size, and one may suspect that both length and width of pellets also depend on animal size. However, in this study we do 


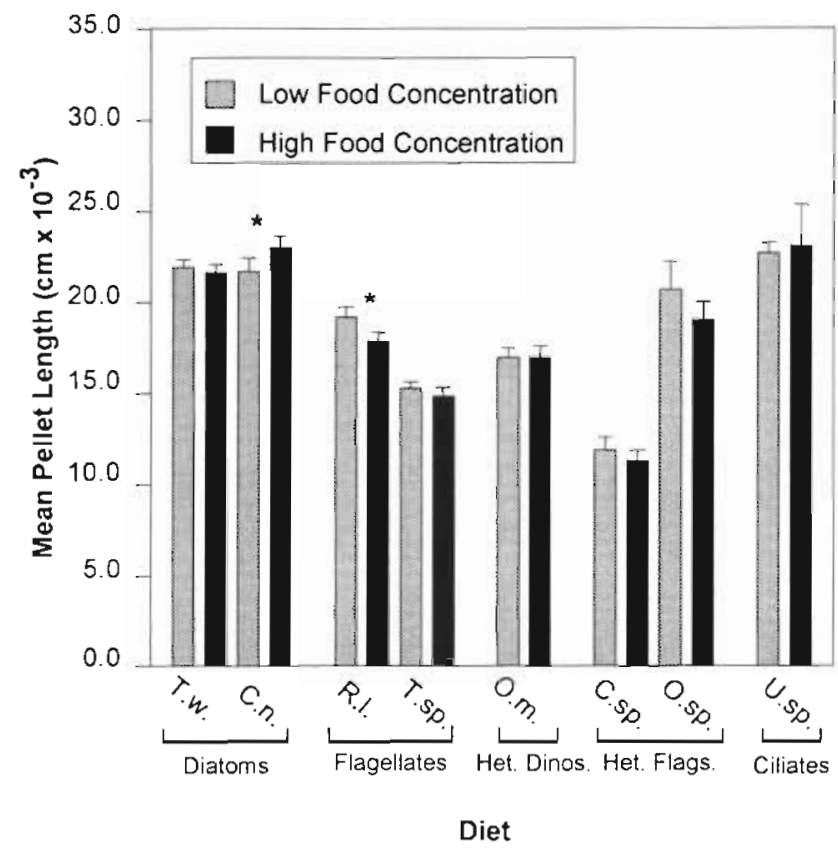

Fig. 1. Acartia tonsa. Mean copepod fecal pellet length as a funtion of diet. Error bars show $95 \%$ confidence interval (CI). T.w. = Thalassiosira weissflogï, C.n. = Chaetoceros neogracile, R.1. = Rhodomonas lens, T.sp. = Tetraselmis sp., O.m. = Oxyrrhis marina, C.sp. = Cafeteria sp., O.sp. = Oikomonas sp. and U.sp. = Uronema sp. *Significant difference $(p<0.05)$ between food concentrations

not report results that have been scaled by copepod size (e.g. pellet length/animal weight or length) for several reasons. First, it is generally inappropriate to use a ratio to scale measurements expected to have an allometric relationship with animal size (see discussion in Dam \& Peterson 1991). Second, both linear and power function fits of pellet length and width versus copepod length and weight yielded significant ( $p<$ $0.05)$, but weak relationships $\left(r^{2}<0.3\right)$. More importantly, the conclusions drawn from data scaled by copepod size varied very little from those for the original measurements. Third, there was no significant relationship between copepod size and fecal pellet density.

\section{Food concentration effects}

In some cases significant differences were found in fecal pellet characteristics with a change in food concentration within a single diet (Figs. 1 to 3). However, these differences did not produce consistent patterns across diets. An increase in food concentration caused increases in pellet size (e.g. pellet length and width for Chaetoceros neogracile) and/or density (e.g. Uronema sp.) for some diets, but decreases for other diets (e.g.
Rhodomonas lens) (Figs. 1 to 3). Pellet lengths and widths appeared generally to parallel each other with respect to food concentration within a diet (Figs. 1\& 2). For instance, fecal pellets from the photosynthetic flagellate diets decreased in both length and width with an increase in food concentration. Because length, width and density of pellets were used in Eq. (2), the same lack of consistent patterns with changes in food concentration appears in the calculated sinking rates for the fecal pellets (Fig. 4). With the exception of the heterotrophic flagellate diets, most differences within and between diets, even when significantly different, were small for all parameters. The pellets produced on the low concentration of Oikomonas sp. seemed different enough from the other pellets to warrant repeating the experiment. However, repeating the experiment did not change the results. When pellets from all experiments were grouped by food concentration, pellet lengths and widths were not significantly different (Mann-Whitney $U$-test $p=0.396$ and $p=0.386$ respectively). However, for both pellet density and sinking rate, the values for the low food concentration as a whole were significantly higher (Mann-Whitney $U$-test $p<0.01$ ) than those for the high food concentration.

When the results from all diets were combined, there was no clear linear relationship between the measured $\mathrm{C}$ and $\mathrm{N}$ concentrations of the food and the mean pellet width, density, and sinking rate (data not shown)

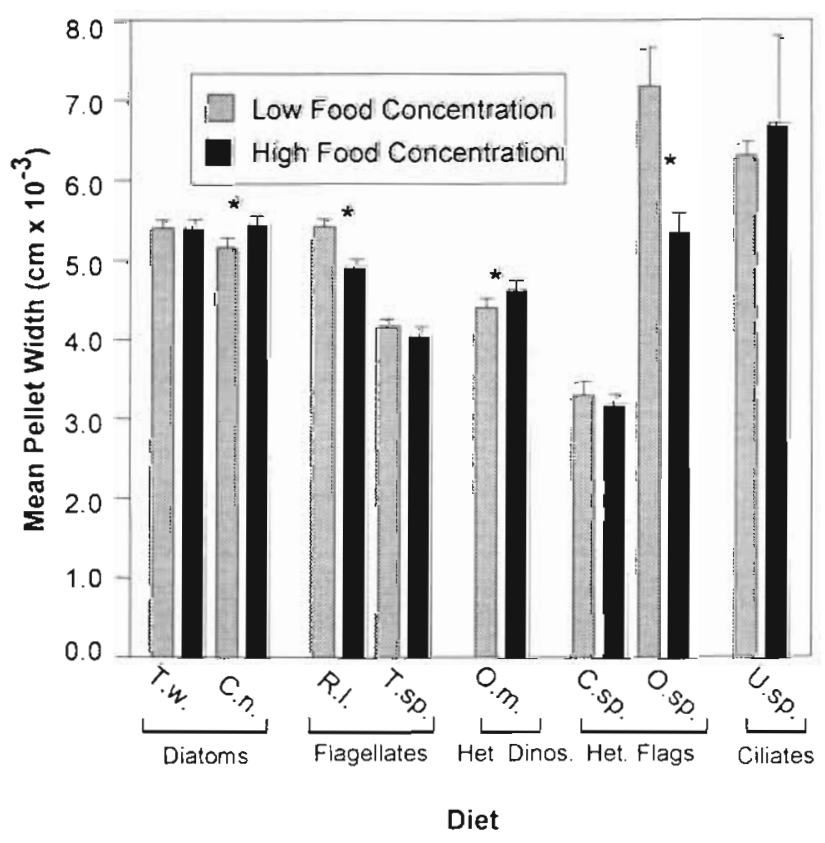

Fig. 2. Acartia tonsa. Mean copepod fecal pellet width as a funtion of diet. Error bars show $95 \% \mathrm{Cl}$. Species abbreviations as in Fig. 1. * Significant difference $(p<0.05)$ between food concentrations 


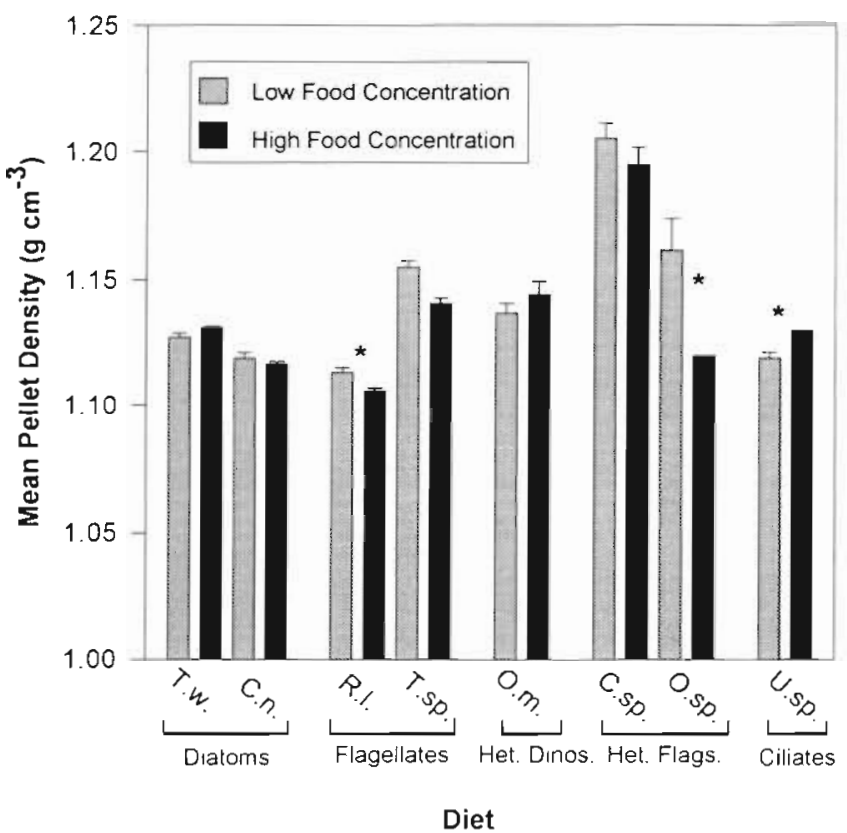

Fig. 3. Acartia tonsa. Mean copepod fecal pellet density as a function of diet. Error bars show $95 \% \mathrm{CI}$. Species abbreviations as in Fig. 1. * Significant difference $(p<0.05)$ between food concentrations

Only in the case of pellet length was the relationship to $\mathrm{C}$ and $\mathrm{N}$ concentration significant $(\mathrm{p}=0.045)$, but the unexplained variance was large $\left(\mathrm{r}^{2}=0.26\right)$.

\section{Diet effects}

For all fecal pellet characteristics (length, width, density and sinking rate) the Kruskal-Wallis tests showed significant differences due to diet. Pairwise comparisons with the Mann-Whitney $U$-test showed that pellet lengths were significantly different for all diets except for the 2 diatoms (Chaetoceros neogracile and Thalassiosira weissflogii) and C. neogracile and the scuticocil-

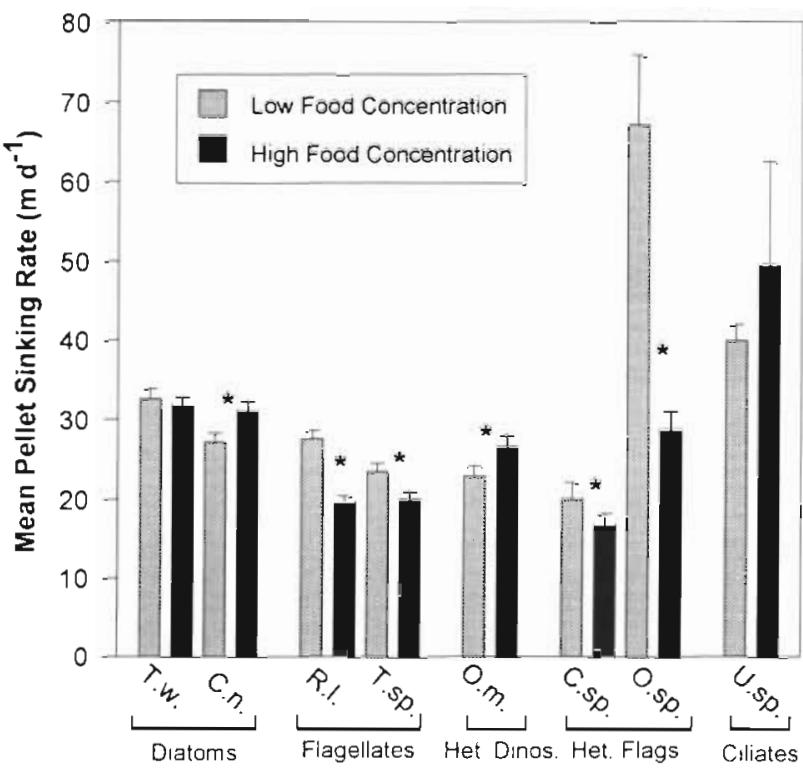

Diet

Fig. 4. Acartia tonsa. Mean copepod fecal pellet sinking rate as a function of diet. Error bars show $95 \% \mathrm{Cl}$. Species abbreviations as in Fig. 1 * Significant difference $(p<0.05)$ between food concentrations

iate Uronemasp. (Table 2). Pellet widths showed many significant differences among diets, with the exceptions that $C$. neogracile was not significantly different from Rhodomonas lens or $T$. weissflogii and Uronema sp. was not significantly different from Oikomonas sp. (Table 2). The densities of fecal pellets produced from $T$, weissflogii, Oxyrrhis marina and Oikomonas sp. diets were not significantly different from each other and neither were the densities of pellets produced by $C$. neogracile and Uronemasp., but those of all other diets were significantly different (Table 2). All of the diets resulted in significantly different fecal pellet sinking rates except for 2 pairs: Rhodomonas lens and $O$. marina, and Oikomonas sp. and Uronema sp. (Table 2).

Table 2. Ranking of copepod fecal pellet characteristics by diet. Rank is in descending order from the top of the columns. All diets are significantly different ( $p<0.05$ ) except those linked by a vertical line

\begin{tabular}{|c|c|c|c|}
\hline Length & Width & Density & Sinking rate \\
\hline Uronemasp. & Uronema sp. & Cafeteriasp. & Oikomonas sp. \\
\hline Chaetoceros neogracile & Oikomonas sp. & Tetraselmis sp. & Uronema sp. \\
\hline Thalassiosira weissflogii & $T$ weissflogii & Oikomonas sp & $T$ weissflogii \\
\hline Oikomonas sp. & C. neogracile & $T$ weissflogii & C. neogracile \\
\hline Rhodomonas lens & R. lens & O. marina & R. lens \\
\hline Oxyrrhis manna & o. marina & C. neogracile & o. marina \\
\hline Tetraselmis sp. & Tetraselmis sp. & Uronerna sp. & Tetraselmis sp. \\
\hline Cafeteria sp. & Cafeteria sp. & R. lens & Cafeteria sp. \\
\hline
\end{tabular}


Overall, Uronema sp. and Chaetoceros neogracile diets resulted in the longest pellets and a diet of Cafeteria sp. resulted in the shortest pellets. The widest fecal pellets were produced when Acartia tonsa was fed either Uronema sp. or Oikomonas sp. and the narrowest pellets were produced when they were fed Cafeteria sp. The most dense pellets were produced from the Cafeteria sp. diet and the least dense were a result of the Rhodomonas lens diet. For the calculated sinking velocities, diets of Uronema sp. and Oikomonas sp. resulted in the highest rates and a diet of Cafeteria sp. resulted in the slowest sinking pellets.

Collectively, there was moderate to little variation in the fecal pellet parameters measured in this study (Table 3 ). Pellet lengths and widths for all pellets measured had coefficients of variation below $25 \%$, and were nearly an order of magnitude more variable than pellet densities. Variability in sinking rates was the highest $(\mathrm{CV}=38 \%)$.

When categorized by functional group (diatoms, photosynthetic flagellates, heterotrophic dinoflagellates, heterotrophic flagellates and ciliates) significant differences were found in fecal pellet characteristics (Table 4). Pellet length and width differed among all groups except for the photosynthetic flagellate and the heterotrophic dinoflagellate diets. All groups had significantly different densities except for the diatom and the photosynthetic flagellate diets. Sinking rates were significantly different for all but the photosynthetic flagellate and heterotrophic flagellate diets. Rankings of these functional groups are shown for each pellet characteristic in Table 4.

Table 3. Coefficient of variation $(\mathrm{CV})([\mathrm{SD} / \mathrm{mean}) \times 100)$ for pellet characteristics of copepod fecal pellets measured in all experiments

\begin{tabular}{|lc|}
\hline Characteristic & CV $(\%)$ \\
\hline Length & 24.1 \\
Width & 21.8 \\
Density & 2.7 \\
Sinking rate & 37.9 \\
\hline
\end{tabular}

\section{DISCUSSION}

Previous studies of zooplankton fecal pellets indicate that food type, quality and quantity affect the fecal pellet parameters that drive sinking velocities (Turner 1977, Bienfang 1980, Dagg \& Walser 1986, Forsyth \& James 1990, Tsuda \& Nemoto 1990, Dilling \& Alldredge 1993, Urban et al. 1993, Butler \& Dam 1994). Given that most copepods feed on a taxonomically diverse diet (Turner 1984, Kleppel 1993), there is a question as to whether changes in fecal pellet characteristics can be explicitly attributed to specific diet types. Prior studies vary greatly in methodology and often consider only 1 or 2 diets. Thus, inter-comparison is difficult. A main goal of this study was to be able to compare changes in pellet characteristics associated with diet. We were able to do this through controlled laboratory experiments of several autotrophic and heterotrophic diets.

Our results indicate that pellet characteristics do change significantly with changes in diet at 'low' and 'high' food concentrations. We can therefore reject our null hypothesis. Though these differences clearly exist, we find that they are mostly small (Tables $2 \& 3$ ) and that the pellet characteristics do not always change in a consistent manner with the specific diets or concentrations used. Below we consider the sources of variation in our measurements and the potential fates of fecal pellets from this study given the range of calculated sinking rates.

Since significant differences in sinking rates were found for nearly all diets and food concentrations we will consider the sources of variability which contribute to these differences. Pellet lengths are the most variable of the measurements in this study, closely followed by pellet widths, both of which are an order of magnitude greater in variability than fecal pellet densities (Table 3). However, the sinking velocity equation used to predict sinking rates in this study (Eq. 2), is far more sensitive to pellet density and width than to pellet length. Keeping all other parameters constant, a $10 \%$ increase in pellet length increases the sinking rate by only $3.3 \%$. The same $10 \%$ increase in pellet width or density would result,

Table 4. Ranking of copepod fecal pellet characteristics by diet functional group. Rank is in descending order from the top of the columns. All groups are significantly different $(p<0.05)$ except where linked by a vertical line

\begin{tabular}{|lll|}
\hline Length and width & Density & Sinking rate \\
\hline Ciliates & Heterotrophic flagellates & Ciliates \\
Diatoms & Heterotrophic dinoflagellates & Diatoms \\
Photosynthetic flagellates & Photosynthetic flagellates & Photosynthetic flagellates \\
Heterotrophic dinoflagellates & Diatoms & Heterotrophic flagellates \\
Heterotrophic flagellates & Ciliates & Heterotrophic dinoflagellates \\
\hline
\end{tabular}


respectively, in a 17.2 or $105 \%$ increase in sinking rate. Given the observed variation of the different parameters (Table 3) and the relative sensitivity of the equation to changes in these parameters, it appears that width is the most influential parameter in the estimation of sinking rates. This helps to explain why diets that resulted in the largest pellets (ciliates and diatoms) rather than those that resulted in the most dense pellets (heterotrophic flagellates and heterotrophic dinoflagellates) are associated with the highest sinking rates (Table 4). It is interesting that pellet density appears to be inversely related to pellet size (Table 4). In fact, pellet density is more consistently related to pellet size than to the type or size of food consumed. For example, diet of ciliates and the 2 sizes of diatom produced the least dense pellets in this study (Table 4). Larger pellets appear to be less densely packed than smaller pellets. Examination of Figs. 1 \& 2 reveals that pellet length and width respond quite similarly to different diets, and to food concentration within a diet. Thus, it appears that the combination of pellet width and length overrides the effect of pellet density on sinking rate. From the relationship density = mass/volume, we calculated the mass of pellets (data not shown; volume estimated from length and width assuming that pellets were cylinders). Though pellet volume and density were inversely related, they did not appear to be proportional since pellet mass did not remain constant. Therefore, the density and dimensions of pellets must be measured to calculate their gravitational sinking velocity.

Past studies have shown an increase in pellet size with increasing food concentration (Dagg \& Walser 1986, Tsuda \& Nemoto 1990, Butler \& Dam 1994), a relationship that was not always observed in this study (Figs. 1 \& 2). Within individual diets, most pellet lengths were not significantly different even with a 5 -fold change in food concentration. For the 2 diets that did show significant differences (Chaetoceros neogracile and Rhodomonas lens), one increased in length with an increase in concentration, and the other decreased. For pellet widths, half of the diets that produced significant differences with changes in food concentration increased with a 5-fold increase in food concentration and half decreased. Elemental analysis of the diets (Table 1) showed that the food concentrations for the low food treatment were typically higher than the nominal value of $100 \mu \mathrm{g} \mathrm{C}^{-1}$ chosen as a limiting food concentration. The possibility exists that both of the food concentrations used for any given diet might have been saturating concentrations. In this case we would not expect to see any difference in pellet size, regardless of the large difference in food concentration available.
Thalassiosira weissflogii is the diet for which we have the most information for Acartia tonsa, in that both ingestion and pellet production functional responses are available in the literature (Houde \& Roman 1987, Butler \& Dam 1994). According to the functional response for ingestion, saturation is not reached until a concentration of $245 \mu \mathrm{g} \mathrm{C}^{-1}$ (Houde \& Roman 1987), which is higher than the actual 'limiting'

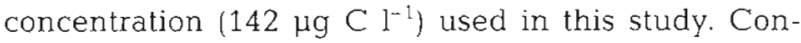
trary to this ingestion response, the saturating concentration for fecal pellet production determined by Butler \& Dam (1994) was approximately $135 \mu \mathrm{g} \mathrm{Cl}^{-1}$, which is very close to the concentration we used. Hence, not only is there a wide range of saturating ingestion concentrations for different diets (Houde \& Roman 1987), but it appears that the functional responses of ingestion and egestion may not always be coupled within a diet. Functional responses are not available for pellet production on all of the diets used in this study, making it impossible to know exactly where on the curve the actual concentrations would fall. Further studies are needed to establish the functional relationship of pellet production rates to food concentration.

The results from the heterotrophic flagellate and ciliate diets are of special interest since the effects of bacterivorous protozoan diets on copepod fecal pellet characteristics, to our knowledge, have not previously been studied experimentally. When compared as functional groups, the heterotrophic flagellate and ciliate diets are significantly different in all measurements (Table 4). However, inspection of Table 2 shows that the ciliate (Uronema sp.) and one of the heterotrophic flagellate diets (Oikomonas sp.) produce fairly similar pellets. In fact, the pellet widths and sinking rates for these 2 diets are statistically indistinguishable. Pellet lengths and densities for these 2 diets are close to the mean for all experiments, but widths and sinking rates are significantly higher. Contrary to these results, the other heterotrophic flagellate diet, Cafeteria sp., resulted in exceptionally small and dense pellets with below-average sinking rates. We have no explanation for these differences.

To explore the fate of fecal pellets from different diets, one needs to consider both sinking and degradation rates of pellets. The gravitational sinking velocity estimates are assumed to be maximum rates since they represent the sinking of pellets, without any change in their integrity, in quiescent, isopycnal waters. Keeping these limitations in mind, these sinking velocities are considered first-order approximations for the purpose of discussion.

Fecal pellet degradation rates are highly temperature dependent and should sharply decrease once pellets leave the warmer surface waters (Honjo \& Roman 1978. Turner 1979. Roy \& Poulet 1990). It is therefore 
most relevant to consider the degree of degradation found in the period necessary for pellets to sink out of the mixed layer. Consideration of the combined sinking and degradation rates allows us to contemplate how differences within the range of results of this study might affect the fate of these fecal pellets. Fecal pellet degradation rates, like sinking rates, are influenced by diet (Lee \& Fisher 1992, Hansen et al. 1996). Hansen et al. (1996) determined fecal pellet degradation rates for Acartia tonsa based on loss of volume (at $18^{\circ} \mathrm{C}$ ) that were not significantly different from the degradation rates based on a carbon:volume ratio. The highest pellet degradation rate was for a diet of the photosynthetic nanoflagellate Rhodomonas baltica and the lowest rate was for a diet of Thalassiosira weissflogii. The rates given in Hansen et al. (1996) were low compared to those found by Lee \& Fisher (1992), but high compared to those measured by Jacobsen \& Azam (1984) and Lampitt et al. (1990). Given the lack of consensus, we used degradation rates from Hansen et al. (1996), as they were measured under conditions most similar to those used in this study.

Since Hansen et al. (1996) measured nearly equivalent degradation rates for the flagellate (fast degradation rate) and a dinoflagellate diet and suggested that the mere presence of ciliates and heterotrophic flagellates in the pellet incubations hastened the degradation process, we will assume that the 'high degradation rate' applies to all but the diatom diets in this study. Dividing the degradation constant, $R\left(t^{-1}\right)$, by the mean estimated sinking rates, $\bar{V}$, for each treatment (Fig. 4), we calculate the L-ratio, a reciprocal length scale which represents the fraction of pellet degradation by unit length traveled. We can use the L-ratio to compare the combined effects of diet-specific sinking and degradation rates for each treatment (Table 5).

Pellets from diatom diets have the smallest L-ratios and thus would be expected to degrade the least per meter traveled. Sinking rates for these pellets are near the average of all treatments, thus the exceptionally low L-ratio is mainly a function of the low degradation rate constant for these diets. Since the L-ratios for all other diets are calculated using the same degradation constant, differences in these ratios are due solely to the differences found in estimated sinking rates from this study

The significance of the L-ratio can be illustrated by considering the degree of degradation a pellet experiences within the mixed layer. For instance, if one assumed that pellets produced at the surface sank through the mixed layer (e.g. $30 \mathrm{~m}$ mixed layer), the degree of degradation would be the product of the $\mathrm{L}$ ratio times the depth of the mixed layer. Such calculation suggests that some diets would result in pellets that would be substantially recycled whereas others
Table 5. The L-ratio $\left(\mathrm{m}^{-1}\right)$, the degradation rate constant, $R$ $\left(t^{-1}\right)$, divided by the mean estimated sinking rate, $\bar{V}\left(\mathrm{~m} \mathrm{~d}^{-1}\right)$. for each diet. $R=0.024 \mathrm{~d}^{-1}$ is used for the diatoms and $R=0.24$ $\mathrm{d}^{-1}$ is used for all other diets. These rate constants correspond to values derived for Thalassiosira weissflogii and Rhodomonas baltica, respectively, by Hansen et al. (1996). Genera given in Table 1

\begin{tabular}{|lcc|}
\cline { 2 - 3 } Diet & $\begin{array}{c}\text { Low food } \\
\text { concentration }\end{array}$ & $\begin{array}{c}\text { High food } \\
\text { Concentration }\end{array}$ \\
\hline$T$ weissflogii & $7.7 \times 10^{-4}$ & $7.9 \times 10^{-4}$ \\
C. neogracile & $9.5 \times 10^{-4}$ & $8.2 \times 10^{-4}$ \\
R. lens & $9.0 \times 10^{-3}$ & $1.3 \times 10^{-2}$ \\
Tetraselmis sp. & $9.3 \times 10^{-3}$ & $1.1 \times 10^{-2}$ \\
O. marina & $1.0 \times 10^{-2}$ & $8.6 \times 10^{-3}$ \\
Cafeteria sp. & $1.2 \times 10^{-2}$ & $1.4 \times 10^{-2}$ \\
Oikomonas sp. & $3.3 \times 10^{-3}$ & $8.0 \times 10^{-3}$ \\
Uronema sp. & $6.0 \times 10^{-3}$ & $4.8 \times 10^{-3}$ \\
\hline
\end{tabular}

would result in pellets that would be exported out of the mixed layer relatively undegraded. Examples of the former include the photosynthetic flagellates and the slower sinking heterotrophic diets (e.g. Oxyrrhis marina and Cafeteria sp.). Examples of the latter include the diatoms and the faster sinking heterotrophic diets (e.g. Oikomonas sp. and Uronema sp.).

In summary, there are significant albeit relatively small differences in the fecal pellet parameters determining sinking rates with changes in diet. Based on the results of this study, the highest degree of variability in the mean fecal pellet sinking rates would be associated with the consumption of bacterivorous heterotrophs. The digestive processes leading to differences in pellet characteristics (e.g. gut passage time) associated with different diets require further study. Based on the results of this study, ignoring diet would lead to uncertainties in sinking rates of nearly $40 \%$. When considered in conjunction with diet-dependent fecal pellet degradation rates, the differences in sinking rates shown in this study suggest different fates for pellets produced from different diets. Thus, in modeling fecal pellet flux diet cannot be completely ignored, particularly if diet varies substantially in time and space.

Acknowledgements. Research supported by grant NSF-OCE 9521907 (CAREER) awarded to H.G.D. We thank G. Wikfors, $D$. Caron, and R. Campbell for providing some of the foods used in the experiments and D. Gifford and R. Campbell for advice on culturing protozoa and copepods, respectively. We thank G. McManus and C. Roesler for comments and suggestions on a previous draft of the manuscript and P. Bogden for discussion regarding turbulent mixing. Contribution No. 303 from the MSTC, University of Connecticut. 


\section{LITERATURE CITED}

Berggreen U, Hansen B, Kiørboe T (1988) Food size spectra, ingestion and growth of the copepod Acartia tonsa during development: implications for determination of copepod production. Mar Biol 99:341-352

Bienfang P (1980) Herbivore diet affects fecal pellet settling Can J Fish Aquat Sci 37:1352-1357

Butler M, Dam H (1994) Production rates and characteristics of fecal pellets of the copepod Acartia tonsa under simulated phytoplankton bloom conditions: implications for vertical fluxes. Mar Ecol Prog Ser 114:81-91

Caron DA (1993) Enrichment, isolation and culture of free-living heterotrophic flagellates. In: Kemp PF, Sherr BF, Sherr EB, Cole JJ (eds) Aquatic microbial ecology. Lewis Publishers, Boca Raton, p 77-89

Dagg MJ, Walser WE Jr (1986) The effect of food concentration on fecal pellet size in marine copepods. Limnol Oceanogr 31:1066-1071

Dam H. Peterson W (1991) In situ feeding behavior of the copepod Temora longicornis: effects of seasonal changes in chlorophyll size fractions and female size. Mar Ecol Prog Ser 71:113-123

Dilling L, Alldredge AL (1993) Can chaetognath fecal pellets contribute significantly to carbon flux? Mar Ecol Prog Ser 92:51-58

Durbin AG, Durbin EG, Wlodarczyk E (1990) Diel feeding behavior in the marine copepod Acartia tonsa in relation to food availability. Mar Ecol Prog Ser 68:23-45

Forsyth DJ, James MR (1990) Effect of food type and concentration on production of faecal pellets by Boeckella propinqua. Arch Hydrobiol 119:183-190

Gardner WD (1997) The flux of particles to the deep sea: methods, measurements and mechanisms. Oceanography 10:116-121

Gifford DJ (1993) Isolation and laboratory culture of marine oligotrichous ciliates. In: Kemp PF, Sherr BF, Sherr EB, Cole JJ (eds) Aquatic microbial ecology. Lewis Publishers, Boca Raton, p 103-108

Guillard RRL (1975) Culture of phytoplankton for feeding invertebrates. In: Smith WL, Chanley MH (eds) Culture of marine invertebrates. Plenum Press, New York, p 29-60

Hansen B, Fotel FL, Jensen NJ, Madsen SD (1996) Bacteria associated with a marine planktonic copepod in culture. II. Degradation of fecal pellets produced on a diatom, a nanoflagellate or a dinoflagellate diet. J Plankton Res 18 $275-288$

Honjo S, Roman MR (1978) Marine copepod fecal pellets: production, preservation and sedimentation. J Mar Res 36 $45-57$

Houde SE, Roman MR (1987) Effects of food quality on the functional ingestion response of the copepod Acartia tonsa. Mar Ecol Prog Ser 86:229-238

Jacobsen TR, Azam F (1984) Role of bacteria in copepod fecal pellet decomposition: colonization, growth rates and mineralization. Bull Mar Sci 35:495-502

Kiørboe T, Møhlenberg F. Hamburger K (1985) Bioenergetics of the planktonic copepod Acartia tonsa: relation between feeding, egg production and respiration, and composition of specific dynamic action. Mar Ecol Prog Ser 26:85-97

Kleppel GS (1993) On the diets of calanoid copepods. Mar Ecol Prog Ser 99:183-195

Komar PD, Morse AP, Small LF, Fowler SW (1981) An analysis of sinking rates of natural copepod and euphausid fecal pellets. Limnol Oceanogr 26:172-180

Lampitt RS, Noji T, von Bodungen B (1990) What happens to zooplankton fecal pellets? Implications for material flux. Mar Biol 104:15-23

Lee BG, Fisher NS (1992) Decomposition and release of elements from zooplankton debris. Mar Ecol Prog Ser 88: $117-128$

Mann KH, Lazier JRN (1996) Dynamics of marine ecosystems. Blackwell Science Inc, Cambridge

McCave IN (1975) Vertical flux of particles in the ocean. Deep-Sea Res 22:491-502

Paffenhöfer GA, Knowles SC (1979) Ecological implications of fecal pellet size, production and consumption by copepods. J Mar Res 37:35-48

Pilskaln CH, Honjo S (1987) The fecal pellet fraction of biogeochemical particle fluxes to the deep sea. Global Biogeochem Cycles 1:31-48

Roy S, Poulet SA (1990) Laboratory study of the chemical composition of aging copepod fecal material. J Exp Mar Biol Ecol 135:3-18

Schwinghamer P, Anderson DM, Kulis DM (1991) Separation and concentration of living dinoflagellate resting cysts from marine sedimentation via density-gradient centrifugation. Limnol Oceanogr 36:588-592

Small L, Fowler S, Unlu M (1979) Sinking rates of natural copepod fecal pellets. Mar Biol 51:233-241

Small L, Knauer GA, Tuel. MD (1987) The role of sinking fecal pellets in stratified euphotic zones. Deep-Sea Res 34: $1705-1712$

Stearns DE (1986) Copepod grazing behavior in simulated natural light and its relation to nocturnal feeding. Mar Ecol Prog Ser 30:65-76

Stoecker DK, Gifford DF, Putt M (1994) Preservation of marine planktonic ciliates: losses and cell shrinkage during fixation. Mar Ecol Prog Ser 11.0:293-299

Strathmann RR (1967) Estimating the organic carbon content of phytoplankton from cell volume or plasma volume. Limnol Oceanogr 27:570-576

Tang KW, Dam HG, Feinberg LR (1998) The relative importance of egg production rate, hatching duration and egg sinking in population recruitment of two species of marine copepods. J Plankton Res 20:1971-1987

Tsuda A, Nemoto T (1990) The effect of food concentration on the faecal pellet size of the marine copepod Pseudocalanus newmani Frost. Bull Plankton Soc Jpn 37:83-90

Turner JT (1977) Sinking rates of fecal pellets from the marine copepod Pontella meadii. Mar Biol 40:249-259

Tumer JT (1979\} Microbial attachment to copepod fecal pellets and its possible ecological significance. Trans Am Microsc Soc 98:131-135

Turner JT (1984) The feeding ecology of some zooplankters that are important prey items of larval fish. NOAA Tech Rep NMFS 7:1-28

Turner J, Ferrante J (1979) Zooplankton fecal pellets in aquatic ecosystems. BioSci 29:670-677

Urban JL, Diebel D, Schwinghamer P (1993) Seasonal variations in the densities of fecal pellets produced by Oikopleura vanhoeffeni (C. Larvacea) and Calanus finmarchicus (C. Copepoda). Mar Biol 117:607-613

Uye S, Kaname K (1994) Relations between fecal pellet volume and body size for major zooplankters of the Inland Sea of Japan. J Oceanogr 50:43-49

Submitted: June 19, 1998; Accepted: October 2, 1998

Proofs received from author(s): December 12, 1998 